\title{
Self-incompatibility in Echinacea purpurea
}

\author{
Loren C. Stephens ${ }^{1}$ \\ Department of Horticulture, Iowa State University, 106 Horticulture Hall, \\ Ames, IA 50011
}

Additional index words. Asteraceae, eastern purple coneflower, medicinal plants, ornamental plant breeding, sporophytic self-incompatibility

\begin{abstract}
Progenies derived from self-pollination and parent-offspring backcrosses of Echinacea purpurea (L.) Moench accession PI 631307 revealed that a sporophytic selfincompatibility (SI) system was operating in this germplasm. Offspring of progenies from the original accession were self-incompatible, but most self-pollinations resulted in some self-seed set. One seedling from such a self-pollination was reciprocally crosscompatible with its parent, proving that a sporophytic SI system was operational. The $\mathrm{F}_{3} \mathrm{BC}_{1}$ progeny could be classified into two offspring groups. The first group of two seedlings was reciprocally compatible with its seed parent but reciprocally incompatible with its pollen parent based on stigma collapse of the seed parent florets 2 to 4 days after pollination. The second offspring group of three seedlings was reciprocally incompatible with its seed parent but reciprocally compatible with its pollen parent. Seed set data were in agreement with classification by stigma collapse in seven of 10 backcrosses, including in several reciprocally compatible backcrosses that provided further proof of a sporophytic SI system. Additionally, a $\chi^{2}$ test showed that the data fit a sporophytic SI model with $S$ allele dominance operating in pollen and pistil. Assuming that $S$ allele dominance is widespread within Echinacea purpurea, it should be possible to produce inbred lines by making successive generations of full-sib crosses.
\end{abstract}

Echinacea purpurea is one of several native Echinacea species of the American Great Plains; indeed, wild populations still exist in undisturbed remnants of that ecosystem (McKeown, 1999). American Indians used Echinacea angustifolia DC. for medicinal purposes as did Eclectic practitioners in the late 19 th and early 20 th centuries in the United States (Bone, 2004). The widespread use of E. purpurea as a medicinal plant in Europe is thought to have occurred as a result of confusion with E. angustifolia (Galambosi, 2004). In more recent times, besides its medicinal uses in holistic medicine, E. purpurea has become a popular ornamental perennial grown for its showy flowers produced in the hottest part of the North American summer when few other herbaceous perennials are in full bloom. Asexual propagation is by division of the mature crown, cuttings, or micropropagation (Hartmann et al., 2002). Seed-propagated cultivars of diploid E. purpurea have been

Received for publication 27 Sept. 2007. Accepted for publication 30 Nov. 2007.

Journal paper of the Iowa Agriculture and Home Economics Experiment Station, Ames, IA, and supported by the Hatch Act and State of Iowa funds.

I greatly appreciate additional financial support from the C. E. Watts Foundation and seeds of Echinacea purpurea accession PI 631307 from the USDA-ARS North Central Regional Plant Introduction Station, Iowa State University, Ames, IA. Also, I thank Mark Widrlechner and two anonymous reviewers for useful improvements to the manuscript and Zach Snovelle for technical help.

${ }^{1}$ To whom reprint requests should be addressed; e-mail lcs@iastate.edu commercially produced, but these are not available in as wide a variety of flower types and colors as are the asexual cultivars (Ault, 2006). One of the first commercially successful seed cultivars was 'Magnus', a cultivar with horizontally held ray florets. Unfortunately, this trait, like many others in seedproduced cultivars, is much more variable than in vegetative cultivars (Armitage, 2000). Nevertheless, because of the much lower plant cost and greater availability, demand for seed cultivars continues to be strong. One reason for trait variability in seed-produced cultivars could be the inbreeding barriers that exist in Echinacea germplasm (Ault, 2006). Although poorly understood in Echinacea, one such barrier is assumed to be selfincompatibility (SI) (McKeown, 1999, 2004; Wagenius, 2000).

Self-incompatibility is a natural outbreeding system present in many angiosperms. In diploids, the system is controlled by a single $S$ locus with multiple alleles. The two main types of SI systems operating in higher plants are gametophytic and sporophytic (Brewbaker, 1957). In the gametophytic SI system, there is a recognition that occurs between the gametophytic pollen parent and the sporophytic seed parent. Recognition occurs in such a way that if the $S$ allele of the pollen gametophyte matches either of the $S$ alleles present in the female sporophyte, pollen-tube growth is inhibited or blocked, and successful double fertilization is prevented; in short, an incompatible pollination. A plant with a gametophytic SI system would produce $S_{1}$ and $S_{2}$ pollen gametophytes, neither of which would be compatible in the $S_{1.2}$ seed parent style.
The recognition of SI in a sporophytic system occurs between the stigma of the seed parent and the pollen exine of the pollen parent (Gerstel and Riner, 1950). Because the pollen exine is composed of maternal tissue, an $S_{1.2}$ pollen sporophyte will be incompatible with an $S_{1.2}$ pistil during self-pollination, for example. However, $S$ allele dominance, in which one $S$ allele is dominant to the other, can occur in plants with sporophytic SI systems (Gerstel, 1950; Hughes and Babcock, 1950). For example, pollen from an $S_{1.2}$ parent would be compatible with an $S_{2.2}$ plant if $S_{1}$ were dominant to $S_{2}\left(S_{1}>S_{2}\right)$. If $S_{1}>S_{2}$ in pollen or pistil, but not both, the cross is compatible in one direction but incompatible in the reciprocal direction.

According to Charlesworth (1985), 40 genera of Asteraceae have been shown to possess sporophytic SI. There have been several additions to that list since then (Davidson and Stace, 1986; Friar and LaDoux, 2002; Hiscock, 2000; Young et al., 2000). Although it is generally accepted that SI systems are family-level traits, exceptions do exist (Goodwillie, 1997; Levin, 1993), and no reports have described how the SI system operates in Echinacea. Determining which SI system, gametophytic or sporophytic, operates in a species is important for predicting crossing relationships and breeding opportunities in that species. In particular, determining how SI operates in Echinacea may lead to more uniform cultivars and more efficient seedcultivar production. The objective of this study was to determine the type of SI system operating in an accession of E. purpurea.

\section{Materials and Methods}

Seeds of accession PI 631307 were obtained from the USDA-ARS North Central Regional Plant Introduction Station, Iowa State University, Ames, IA. PI 631307 originated from a subpopulation of a wild population located at the "Christy Road" site in St. Louis County, MO. This accession was chosen because it originated within the core of its native range (McKeown, 1999) and so it would be assumed to be typical for the species. Also, it is unimproved germplasm that would be expected to have natural outcrossing systems unimpaired by selective inbreeding. Finally, this accession's seedlings and subsequent offspring proved adaptable to greenhouse conditions for flowering and seed production. Seeds of 'Magnus' were purchased from Park Seed Co., Greenwood, SC.

Self-pollinations were performed to determine the extent of selfing present in the germplasm throughout the study. One original seedling from the PI 631307 seed sample produced 14 seeds from self-pollination of one inflorescence. Outcrosses confirmed that this selection was both male- and femalefertile with the potential to produce up to 190 seeds per inflorescence. In the progeny growout, seedling $02-2-12$ produced 30 seeds from a self-pollination while also testing male- and female-fertile, suggesting that this germplasm 
contained a working SI system but with the ability to produce some seeds by self-pollination, a common phenomenon among Echinacea species (McKeown, 1999, 2004).

A pedigree of the plants and the order of crosses are shown in Figure 1. Seedling 053-5 was selected based on vigor, good flowering characteristics, and pollen production for selfing to produce the 02-2 progeny. Seedling $02-2-12$ was selfed to produce progeny $03-$ 83. Seedling 03-83-5 was backcrossed to its parent $02-2-12$, giving rise to $\mathrm{F}_{3} \mathrm{BC}_{1}$ progeny 04-31. Five offspring of progeny 04-31 were selected based on vigor, pollen production, and sufficiently long bloom times for backcrossing to testers 03-83-5 and 02-2-12.

Parent-offspring backcrosses can be used to determine the type of SI system operating within a species (Stephens et al., 1984). Three types of crossing schemes served as the experimental framework to distinguish between gametophytic and sporophytic SI in a backcrossing scheme (Fig. 2).

The first crossing scheme assumes a heterozygous parent, e.g., $S_{1.2}$, with a selfpollination yielding $S_{1.1}, S_{1.2}$, and $S_{2.2}$ offspring. Offspring used as seed parents in a backcross to their parent will be compatible in a gametophytic SI system because there will be no barrier to $S_{1}$ pollen tubes in the $S_{2.2}$ pistil and similarly to $S_{2}$ pollen tubes in a $S_{1.1}$ pistil. A backcross is compatible in the sporophytic SI system if $S_{1}>S_{2}$ and $S_{2.2}$ is an offspring backcrossed to the original $S_{1.2}$ parent.

For the second crossing scheme (Fig. 2), and assuming a gametophytic SI system, the $S_{2.2} \times S_{1.2}$ backcross is compatible, whereas its reciprocal $S_{1.2} \times S_{2.2}$ is incompatible. In the sporophytic SI system, $S_{2.2} \times S_{1.2}$ is a compatible backcross only if $S_{1}>S_{2}$ in the pollen. Reciprocal crosses will yield compatible and incompatible results, respectively, if $S$ allele dominance exists in pollen or pistil but not both.

For the third crossing scheme (Fig. 2), the example provided is $\left(S_{2.2} \times S_{1.2}\right) \times S_{1.2}$, a backcross yielding compatible offspring that are backcrossed to the original (pollen) parent. In a gametophytic SI system, all offspring from the original backcross would be $S_{1.2}$, none of which would be compatible in a second backcross to the original (pollen) parent. An exception is that, without emasculation, contaminating self-pollinations would yield $S_{2.2}$ genotypes in the original backcross progeny. If a sporophytic SI system were operating and $S_{1}>S_{2}$, half of the progeny from the first backcross would be expected to be compatible with the original (pollen) parent in the second backcross, assuming no contaminating self-pollinations. By this strategy, tentative $S$ genotypes can be assigned to parents as test crosses to offspring are completed with the parents becoming $S$ genotype testers in subsequent progeny tests.

All plants, whether from seeds or cuttings, were grown under natural photoperiods throughout the year. Seeds were germinated in late October, $\approx 30 \mathrm{~d}$ after harvest. Seed- lings were grown to the four- to six-leaf stage at $17^{\circ} \mathrm{C}$ night temperature, then were placed in a glasshouse with a $7^{\circ} \mathrm{C}$ night temperature until mid-March, when plants were moved back to a glasshouse with a $17{ }^{\circ} \mathrm{C}$ night temperature. Daytime temperatures were maintained from $5^{\circ}$ to $10{ }^{\circ} \mathrm{C}$ higher than nighttime temperatures from October to midMarch. Rapid growth occurred in April and May, bolting in June, and flowering and controlled pollinations in July and August. During the summer, day and night temperatures were controlled only with light glass shading and by side-sash and ridge-vent ambient cooling with temperature peaking above $40{ }^{\circ} \mathrm{C}$ on sunny days. Seeds were harvested 6 to 8 weeks after the last pollination, from early August to late September. After seed harvest, selected plants to be carried into the next growing season were grown under natural photoperiods until new vegetative side shoots appeared near the crown above the soil surface, usually starting in late August. As needed, cuttings of these side shoots were taken, dipped into $0.3 \%$ indolebutyric acid as a talc-powder formulation (Brooker Chemical Corp., N. Hollywood, $\mathrm{CA})$, and placed into coarse perlite under intermittent mist for 3 to 5 weeks. Rooted cuttings were transplanted to $10-\mathrm{cm}$ pots and were grown at $17^{\circ} \mathrm{C}$ night temperature until late December, when plants were placed in the $7{ }^{\circ} \mathrm{C}$ night-temperature glasshouse. In

\begin{tabular}{l|lc} 
& \multicolumn{2}{c}{ Expected Result for the Model } \\
\cline { 2 - 2 } $\begin{array}{l}\text { Crossing } \\
\text { Schemes }\end{array}$ & Gametophytic & Sporophytic \\
\hline $\begin{array}{l}\text { Offspring }\left(S_{1.1}, S_{1.2}, \text { or } S_{2.2}\right) \times \\
\text { heterozygous (het) parent }\left(S_{1.2}\right) \\
\text { is compatible?* }\end{array}$ & yes & yes \\
$\begin{array}{l}\text { Het parent-offspring cross } \\
\text { results are reciprocally } \\
\text { different?** }\end{array}$ & yes & yes \\
$\begin{array}{l}\text { Offspring of compatible } \\
\text { offspring } \times \text { het parent is } \\
\text { compatible in a backcross to } \\
\text { the het parent?** }\end{array}$ & no & yes \\
\end{tabular}

*homozygous offspring from a self pollination will be compatible as seed parent with the het parent in a gametophytic system and homozygous $S_{2.2}$ offspring will be compatible as seed parent with the het parent in a sporophytic system if $S_{1}>S_{2}$ **an $S_{2.2} \times S_{1.2}$ backcross is compatible but its reciprocal is incompatible in a gametophytic system, whereas the same cross in a sporophytic system is compatible only if $S_{1}>S_{2}$ in the pollen and reciprocal differences require $S$ allele dominance to exist in pollen or pistil but not both *** $\left(S_{2.2} \times S_{1.2}\right) \times S_{1.2}$ would be incompatible in a gametophytic system whereas in a sporophytic system with $S_{1}>S_{2}$, half the progeny from the $S_{2.2} \times S_{1.2}$ backcross would be compatible with the $S_{1,2}$ parent in the second backcross

Fig. 2. Comparison of gametophytic and sporophytic one-gene models of self-incompatibility (SI) systems using parent-offspring crosses as a discerning feature. 
mid-March, plants were transferred back to the glasshouse maintained at $17{ }^{\circ} \mathrm{C}$ night temperature, then were shifted to $15-\mathrm{cm}$ pots, and finally to $7571-\mathrm{cm}^{3}$ nursery containers during late spring growth. In this manner, initiation of shoot growth and subsequent flowering of both vegetatively and seedpropagated plants could be synchronized each growing season.

The growing medium was LC1, composed of $70 \%$ to $80 \%$ sphagnum peatmoss, with the remaining volume perlite, and $\mathrm{pH}$ adjusted with dolomitic limestone (Sun Gro Horticulture Ltd., Bellevue, WA). Balanced fertilizer solutions were added to irrigation water to keep the electrical conductivity in the range of 1.0 to $2.0 \mathrm{mS} \cdot \mathrm{cm}^{-1}$ for young seedlings and winter-grown plants, based on the pour-through method (Cavins et al., 2005 ), and in the range of 2.0 to $3.0 \mathrm{mS} \cdot \mathrm{cm}^{-1}$ for rapidly growing and bolting plants. Ammonium-based and nitrate-based complete fertilizer solutions were used alternately to keep the $\mathrm{pH}$ in a range from 5.8 to 6.5 . A soil test was performed each season at the start of bolting to confirm that no nutrients were deficient.

To control height, plants were sprayed to glistening on the shoot apex and surrounding leaves with $250 \mathrm{mg} \cdot \mathrm{L}^{-1}$ daminozide $(\mathrm{N}$-dimethylaminosuccinamic acid; Uniroyal Chemical Co., Middlebury, CT) from the start of bolting until the setting of the terminal-inflorescence bud. In addition, budded plants were sprayed to glistening on the foliage weekly with $400 \mathrm{mg} \cdot \mathrm{L}^{-1}$ calcium in an aqueous calcium chloride solution until color changed from green to pink in ray florets of flower (inflorescence) buds to ensure that calcium deficiency would not occur in the terminalinflorescence bud during rapid bolting.
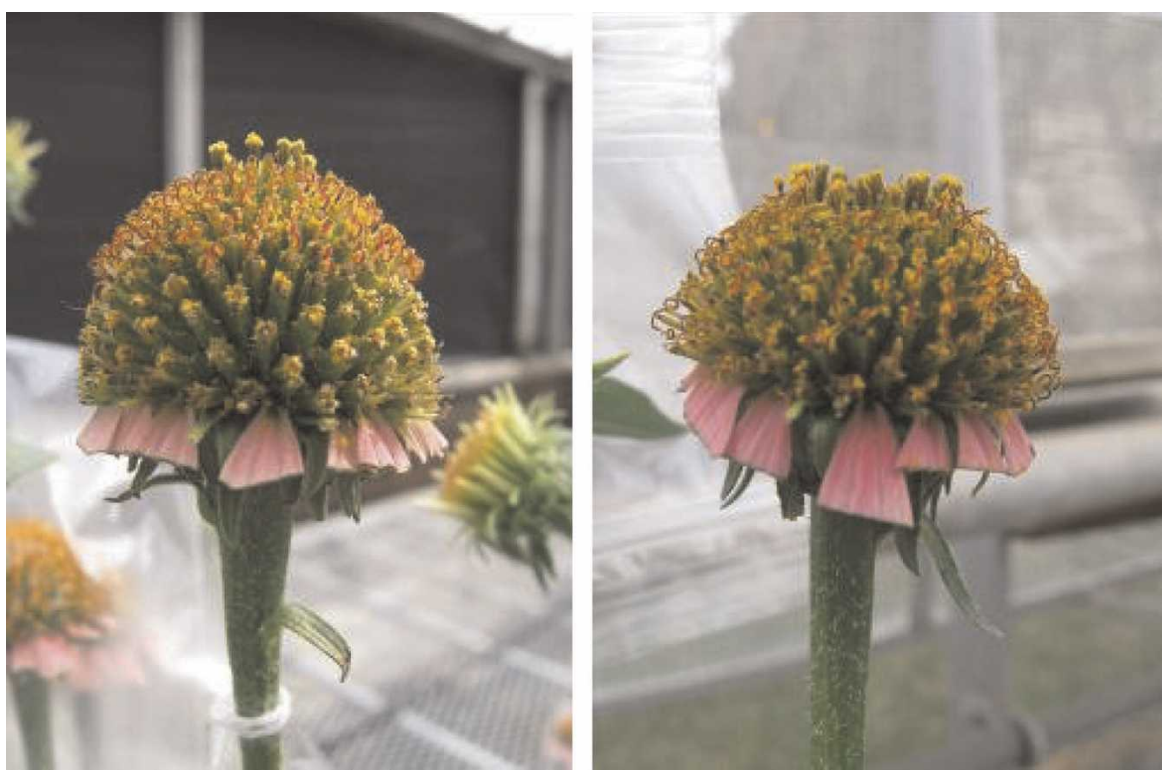

Fig. 3. Compatible (left) cross showing collapsed stigmas on the outer (first-to-open) floret rows of the inflorescence $3 \mathrm{~d}$ after pollination and incompatible (right) cross showing uncollapsed stigmas on Echinacea purpurea inflorescences. Pales (long, sharp receptacle bracts) were removed before bud break to make stigmas more easily visible.

applied with a No. 3 camel-hair brush, which was dipped in $70 \%$ ethanol and dried thoroughly between pollinations.

Compatible crosses exhibited collapsed stigmas 2 to $4 \mathrm{~d}$ after pollination (Fig. 3). Stigmas pollinated by pollen from incompatible crosses and selfs, and stigmas of unpollinated florets, maintained turgor for 12 to $14 \mathrm{~d}$ after floret opening. This visual difference of appearance between compatible and incompatible cross, hereafter referred to as the stigma test, provided a means of quickly assessing crosscompatibility. Seeds from each pollinated inflorescence were counted after ripening and drying as another measure of compatibility, although the stigma test was considered a more reliable indicator because of less environmental and no seed-development variation. Also, stigma collapse has been observed as a reliable indicator of crosscompatibility in E. angustifolia (Wagenius, 2000).
Student $t$ tests were performed on seed set data to detect significant differences between SI and crosscompatible pollinations and between cross-incompatible and crosscompatible pollinations by using Microsoft Office Excel software (Microsoft Corporation, 2003). Unpaired $t$ tests were used, and analysis was performed assuming unequal variances because of inherently larger variances for compatible as opposed to incompatible crosses or selfs. Degrees of freedom for each $t$ test varied from 3 to 10 , depending on the number of replications for each cross. Calculated $t$ values were compared with twotailed tabulated $t$ values at the 5\% and $1 \%$ probability levels. $\chi^{2}$ tests were performed according to Steel and Torrie (1960).

\section{Results and Discussion}

Seedling 02-2-12 and its offspring 03-835 were both SI, but the $02-2-12 \times 03-83-5$ backcross was reciprocally crosscompatible based on the stigma test (Table 1). Seed set was significantly greater for compatible crosses compared with incompatible selfpollinations (Table 1), indicating that sporophytic SI was operating in these plants along with $S$ allele dominance in both pollen and pistil (Fig. 2). Furthermore, the fact that there were no reciprocal differences is contrary to the prediction that a gametophytic SI system is operating (Fig. 2).

Self-pollination of $\mathrm{F}_{3} \mathrm{BC}_{1}$ offspring 04$31-3,-4,-7,-9$, and -11 over the two crossing seasons of 2005 and 2006 produced means of one, seven, 10, three, and three seeds per inflorescence, based on four to 12 replications, with an overall progeny mean of five seeds per inflorescence indicating that, like the parents, the offspring were also SI. Two $\mathrm{F}_{3} \mathrm{BC}_{1}$ offspring, 04-31-4 and 04-31-11, were crosscompatible as pollen parents with parent tester 03-83-5 as the seed parent, but both were cross-incompatible with parent tester $02-2-12$ as the seed parent based on the stigma test (Table 2). Three $\mathrm{F}_{3} \mathrm{BC}_{1}$ offspring, 04-31-3, 04-31-7, and 04-31-9, were crosscompatible with the parent tester $02-2-12$ as the seed parent, but all were cross-incompatible with parent tester $03-83-5$ as the seed parent based on the stigma test. Based on seed set, a $t$ test showed a significant difference between compatible and incompatible parent tester $\times$ offspring crosses for four of the $5 \mathrm{~F}_{3} \mathrm{BC}_{1}$ offspring with only 04-31-3 showing no significant difference in seed set regardless of which parent tester was used as

Table 1. Selfs and reciprocal parent $\times$ offspring $(02-2-12 \times 03-83-5)$ backcrosses $^{z}$

\begin{tabular}{|c|c|c|c|}
\hline 0 & $02-2-12$ & $03-83-5$ & $\mathrm{t}$ \\
\hline $02-2-12$ & $1(-)$ & $66(+)$ & $5.02 *$ \\
\hline $03-83-5$ & $66(+)$ & $4(-)$ & $4.31 * *$ \\
\hline $\mathrm{t}$ & $4.63 * *$ & $4.65^{*}$ & \\
\hline
\end{tabular}

${ }^{\mathrm{z}}$ Mean no. of seeds per inflorescence. Incompatible $(-)$ or compatible $(+)$ cross is based on stigma collapse 2 to $4 \mathrm{~d}$ after first pollination.

${ }^{*, * *}$ Significant at $P \leq 0.05$ and 0.01 , respectively. 
Table 2. Parent-offspring crosses using parent testers (02-2-12 and 03-83-5) as seed parents over two crossing seasons ${ }^{\mathrm{z}}$

\begin{tabular}{|c|c|c|c|c|c|c|}
\hline $0 \hat{0}$ & $04-31-4$ & 04-31-11 & $04-31-3$ & $04-31-7$ & $04-31-9$ & Magnus Outcross \\
\hline $02-2-12$ & $16(-)$ & $21(-)$ & $23(+)$ & $77(+)$ & $88(+)$ & $74(+)$ \\
\hline $03-83-5$ & $71(+)$ & $81(+)$ & $14(-)$ & $21(-)$ & $3(-)$ & $100(+)$ \\
\hline $\mathrm{t}$ & $2.77 *$ & $5.12 * *$ & $0.94 \mathrm{NS}$ & $3.07 *$ & $8.45^{* *}$ & \\
\hline
\end{tabular}

${ }^{\mathrm{z}}$ Mean no. of seeds per inflorescence. Incompatible $(-)$ or compatible $(+)$ cross is based on stigma collapse 2 to $4 \mathrm{~d}$ after first pollination.

NS, ${ }^{*}{ }^{* *}$ Nonsignificant or significant at $P \leq 0.05$ or 0.01 , respectively.

the seed parent (Table 2). Seedling 04-31-3 produced sparse pollen in the 2005 and 2006 crossing seasons, despite its selection for good pollen production in 2004. Thus, insufficient pollen may have led to poor seed set on tester $02-2-12$, a putative compatible cross. Overall, however, stigma tests and seed set data were in agreement.

For the reciprocal crosses, $\mathrm{F}_{3} \mathrm{BC}_{1}$ offspring 04-31-4 and -11 formed a grouping of offspring that were compatible and incompatible as seed parents with parent testers 03-83-5 and 02-2-12, respectively, whereas seedlings $04-31-3,-7$, and -9 formed a grouping of offspring compatible and incompatible as seed parents with parent testers $02-2-12$ and $03-83-5$, respectively, based on the stigma test (Table 3 ). As expected for seedlings $04-31-3,-7$, and -9 as seed parents, compatible crosses with parent testers resulted in significantly greater seed set compared with incompatible crosses. However, for seedlings 04-31-4 and -11, seed set of compatible crosses as seed parents with parent testers was not significantly different compared with incompatible crosses. Seedlings 04-31-4 and -11 had unusually large variation in seed set, which contributed to inconclusive $t$ tests. One reason may have been that some test crosses were done at the beginning of the crossing season, whereas others were done near the end, leading to potential differences in pollen viability and seed-setting ability that may have varied widely over the crossing season. Additionally, high temperatures occurred regularly during the time seedlings 04-31-4 and -11 were in bloom, perhaps resulting in unusually high numbers of self seeds [known as pseudoselfcompatibiltiy (PSC)], which would have masked the incompatible cross with pollen tester 02-2-12. High temperatures are known to be a cause of PSC, resulting from

Table 3. Parent-offspring crosses using parent testers $(02-2-12$ and $03-83-5)$ as pollen parents over two crossing seasons ${ }^{2}$.

\begin{tabular}{lrrr}
\hline & $02-2-12$ & $03-83-5$ & $\mathrm{t}$ \\
\hline $04-31-4$ & $38(-)$ & $34(+)$ & $0.34 \mathrm{NS}$ \\
$04-31-11$ & $30(-)$ & $56(+)$ & $0.19 \mathrm{~ns}$ \\
$04-31-3$ & $30(+)$ & $13(-)$ & $2.62^{*}$ \\
$04-31-7$ & $110(+)$ & $3(-)$ & $3.87^{*}$ \\
$04-31-9$ & $106(+)$ & $9(-)$ & $5.54^{* *}$
\end{tabular}

${ }^{\mathrm{z}}$ Mean no. of seeds per inflorescence. Incompatible $(-)$ or compatible $(+)$ cross is based on stigma collapse 2 to $4 \mathrm{~d}$ after first pollination.

${ }^{\mathrm{Ns}, *, * *}$ Nonsignificant or significant at $P \leq 0.05$ or 0.01 , respectively the breakdown of the SI reaction (Ascher, 1976). Notwithstanding the discrepancies in stigma tests and seed set data involving seedlings $04-31-3,-4$, and -11 , reciprocally compatible crosses of 02-2-12 with 04-31-7 and -9 is confirmation that a sporophytic SI system is operating in this germplasm (Tables 2 and 3; Fig. 2).

A working hypothesis was constructed to fit the available data. The original selected SI seedling has a sporophytic SI system and is heterozygous, here designated $S_{1.2}$ (Fig. 4). Self-pollination of the original seedling resulted in seedling 02-2-12, which is also an $S_{1.2}$ heterozygote. Seedling 02-2-12 was selfed, resulting in progeny 03-83. One of the seedlings of that progeny, 03-83-5, was crosscompatible with its heterozygous parent 02-2-12, so 03-83-5 must be $S_{2.2}$ under the assumption that $S_{1}>S_{2}$. Seedlings of progeny 04-31 were grown out and test-crossed to both parent testers to determine each $S$ genotype with the working hypothesis predicting that roughly half of the progeny would be $S_{1.2}$ and the other half $S_{2.2}$. Using collapsed stigmas as an indicator of crosscompatibility, 04-31-4 and -11 could be classified as $S_{1.2}$ because they were both reciprocally incompatible with parent tester

\section{PI 631307-053-5 seedling $\left(S_{1.2}\right)$}

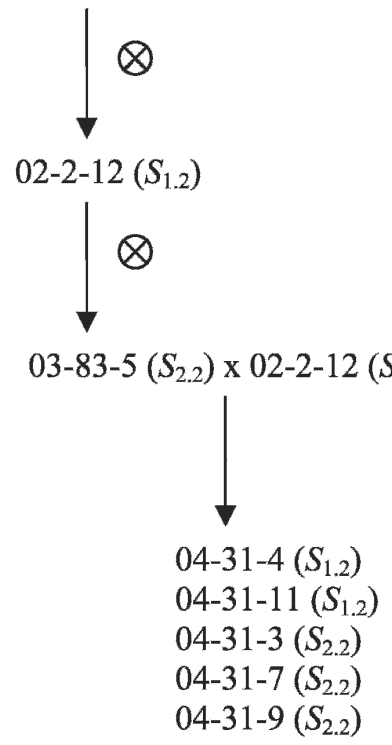

Fig. 4. Proposed model for $S$ genotypes of Echinacea purpurea and crossing behavior of PI 631307-053-5 accession seedling and its offspring assuming a sporophytic SI system.
02-2-12, whereas 04-31-3, -7, and -9 could be classified as $S_{2.2}$ because they were all reciprocally incompatible with 03-83-5 (Tables 2,3 , and 4). A $\chi^{2}$ test showed that the 04-31 seedlings segregated in the expected 12:13 ratio of $S_{1.2}: S_{2.2}$ genotypes, assuming the operation of a sporophytic SI system and a $1: 1$ genetic ratio of $S_{1.2}: S_{2.2}$ genotypes with $4 \% S_{2.2}$ genotypes from natural selfing of 03 83-5 (Tables 1 and 4). Percent selfing of 0383-5 was based on the mean number of seeds from self-pollination (Table 1), expressed as the percent of a compatible outcross (Table 2). A gametophytic model would predict a $24: 1$ ratio of $S_{1.2}: S_{2.2}$ genotypes in the 04-31 progeny with all $S_{2.2}$ genotypes being the result of 03-83-5 selfing (Fig. 2; Table 1). However, the observed ratio differed significantly from that expectation (Table 4) when a $\chi^{2}$ test was applied to the data (not shown).

According to the foregoing $S$ genotype classification, $\mathrm{F}_{3} \mathrm{BC}_{1}$ offspring 04-31-7 should be $S_{2.2}$ and its sibling 04-31-4 should be $S_{1.2}$. As a test of this hypothesis, the cross 04-31-7 × 04-31-4 was made and replicated several times to see if it was compatible. As expected, stigmas of 04-31-7 collapsed 2 to $4 \mathrm{~d}$ after pollination with $04-31-4$. Of six crosses performed over the 2006 crossing season, the number of seeds produced per inflorescence varied from 44 to 140 (mean, 103), demonstrating that this was a compatible cross, as predicted. This result demonstrates that inbreeding by using full-sib crosses is feasible following a similar proposed scheme for garden chrysanthemum (Stephens et al., 1984). Identification of $S_{2.2}$ and $S_{1.2}$ genotypes among sibs should be relatively easy because of the roughly $1: 1$ genetic ratio of $S_{1.2}: S_{2.2}$ genotypes in each sexual generation, assuming that all populations of E. purpurea have a sporophytic SI system with similar dominance relationships. Preliminary data (not shown) suggest $S$-allele dominance among related individuals of another unrelated accession and in the commercial cultivar Magnus. Theoretically then, full-sib crosses could be used in successive generations to develop inbred lines, during which desirable traits and strong SI could be selected, potentially resulting in development of better hybrid or synthetic E. purpurea cultivars

Table 4. $\chi^{2}$ analysis of segregating $S$ genotypes in the $04-31 \mathrm{~F}_{3} \mathrm{BC}_{1}$ progeny $\mathrm{z}^{\mathrm{z}}$.

\begin{tabular}{lcc}
\hline$S$ genotypes & Observed & Expected $^{\mathrm{y}}(12: 13)$ \\
\hline$S_{1.2}$ & 2 & 2.4 \\
$S_{2.2}$ & 3 & 2.6 \\
Total & 5 & \\
\multicolumn{2}{c}{$\chi_{\text {(goodness-of-fit) }}$} & $=0.13 \mathrm{NS}$ \\
\hline
\end{tabular}

${ }^{\text {z}}$ Assuming the 03-83-5 seed parent is $S_{2.2}$ and the 02-2-12 pollen parent is $S_{1.2}$.

${ }^{y}$ Assuming a 1:1 genetic ratio of $S_{1.2}: S_{2.2}$ genotypes and $4 \%$ of $S_{2.2}$ genotypes are from self-pollination of unemasculated 03-83-5 florets based on mean selfed seeds (from Table 1 ) as a percent of seeds set from a Magnus outcross (from Table 2).

${ }^{\mathrm{N}}$ Nonsignificant. 


\section{Literature Cited}

Armitage, A. 2000. Perennial genera: Echinacea. Greenhouse Grower 18:120-122.

Ascher, P.D. 1976. Self-incompatibility systems in floriculture crops. Acta Hort. 63:205-215.

Ault, J.R. 2006. Coneflower, p. 799-822. In: Anderson, N.O. (ed.). Flower breeding and genetics. Springer, Dordrecht, The Netherlands.

Bone, K. 2004. Echinacea: Quality, uses, and immunomodulating activity from a phytotherapist's perspective, p. 203-213. In: Miller, S.C. (ed.), Echinacea: The genus Echinacea. CRC Press, Boca Raton, FL.

Brewbaker, J.L. 1957. Pollen cytology and self incompatibility in plants. J. Hered. 48:271-277.

Cavins, T.J., B.E. Whipker, and W.C. Fonteno. 2005. Timing of PourThru affects $\mathrm{pH}$, electrical conductivity, and leachate volume. Commun. Soil Sci. Plant Anal. 36:1573-1581.

Charlesworth, D. 1985. Distribution of dioecy and self-incompatibility in angiosperms, p. 237268. In: Greenway, P.J., P.H. Harvey, and M. Slatkin (eds.). Evolution: Essays in honor of John Maynard Smith. Cambridge University Press, Cambridge, UK.

Davidson, J.K. and H.M. Stace. 1986. Genetics of self-incompatibility in Calotis cuneifolia. J. Hered. 77:471-472.
Friar, E.A. and T. LaDoux. 2002. Genetic control of self-incompatibility in Centromadia (Hemizonia) pungens subsp. laevis (Madiinae, Asteraceae). Aliso 21:1-6.

Galambosi, B. 2004. Cultivation in Europe, p. 2952. In: Miller, S.C. (ed.). Echinacea: The genus Echinacea. CRC Press, Boca Raton, FL.

Gerstel, D.U. 1950. Self-incompatibility studies in guayule. 2: Inheritance. Genetics 35:482506.

Gerstel, D.U. and M.E. Riner. 1950. Self-incompatibility studies in guayule. 1: Pollen-tube behavior. J. Hered. 4:49-55.

Goodwillie, C. 1997. The genetic control of selfincompatibility in Linanthus parviflorus (Polemoniaceae). Heredity 79:424-432.

Hartmann, H.T., D.E. Kester, F.T. Davies, Jr., and R.L. Geneve. 2002. Plant propagation, principles and practices. 7th Ed. Prentiss Hall, Upper Saddle River, NJ.

Hiscock, S.J. 2000. Self-incompatibility in Senecio squalidus L. (Asteraceae). Ann. Bot. (Lond.) 85:(Suppl A):181-190.

Hughes, M.B. and E.B. Babcock. 1950. Selfincompatibility in Crepis foetida (L.) subsp. rhoedifolia. Genetics 35:570-588.

Levin, D.A. 1993. S-gene polymorphism in Phlox drummondi. Heredity 71:193-198.
McKeown, K.A. 1999. Echinacea gives the United States an opportunity to put conservation policies into practice. Diversity 15:17-19.

McKeown, K.A. 2004. A review of preliminary Echinacea genetics and the future potential of genomics, p. 13-20. In: Miller, S.C. (ed.). Echinacea: The genus Echinacea. CRC Press, Boca Raton, FL.

Microsoft Corporation. 2003. Microsoft Office Excel, version 2003. Microsoft Corp., Redmond, WA.

Steel, R.G.D. and J.H. Torrie. 1960. Principles and procedures of statistics. McGraw-Hill, New York, NY.

Stephens, L.C., P.D. Ascher, and R.E. Widmer. 1984. Interaction among sporophytic $S$ loci in self-incompatible garden chrysanthemums. Euphytica 33:623-631.

Wagenius, S. 2000. Performance of a prairie mating system in fragmented habitat: Selfincompatibility and limited pollen dispersal in Echinacea angustifolia. Univ. Minn., St. Paul, PhD Diss. Abstr. AAT 991476.

Young, A., C. Miller, E. Gregory, and A. Langston. 2000. Sporophytic self-incompatibility in diploid and tetraploid races of Rutidosis leptorrhynchoides (Asteraceae). Aust. J. Bot. 48: 667-672. 